retrobulbar needle path length. Ophthalmology 1989; 96 : 1221-4.

2 Wong $D H$. Regional anaesthesia for intraocular surgery. Can J Anaesth 1993; 40: 635-57.

3 Hamilton RC, Gimbel HV, Strunin L. Regional anaesthesia for 12,000 cataract extraction and intraocular lens implantation procedures. Can J Anaesth 1988; 35: 61'5-23

4 Demediuk OM, Dhaliwal RS, Papworth DP, Devenyi RG, Wong CT. A comparison of peribulbar and retrobulbar anesthesia for vitrcoretinal surgical procedures. Arch Ophthalmol 1995; 113: 908-13.

5 Abramson $D C$. Sudden unexpected sneezing during the insertion of peribulbar block under propofol sedation. Can J Anaesth 1995; 42: 740-3.

\section{Postoperative pain management - beyond basics}

\section{To the Editor:}

Butscher $e t$ al. ${ }^{\prime}$ report a technique for intramuscular dosing with morphine based on observed patient requirements in the PACU. They state the technique provides "efficacious and relatively inexpensive postoperative analgesia." Those comments are echoed in an editorial by Moote. ${ }^{2}$ The conclusions of the study relating to efficacy and expense of $i m$ injections, and the related editorial comments (which also include the issuc of safety) should be viewed with caution.

In the Butscher study, it does not appear that patient reports of pain were obtained under standard conditions. An important distinction should be made between rest pain, which is generally easy to control, and incident pain such as that associated with deep breathing, ambulation, or maintenance of a normal range of motion after replacement of a major joini. Adequate control of incident pain is considerably more difficult to achieve than control of rest pain: What kind of pain was studied by Butscher et al.: rest pain, incident pain, or undifferentiated pain? Unless patients were specifically asked to rate their incident pain, the probability is that rest pain was usually reported. Intramuscular injections are not well suited to the control of incident pain. The best than can be done is to regularize the medicating schedule as suggested by Dr. Moote in her editorial. Such an approach may still produce inadequate analgesia for incident pain while imposing excessive doses of medication, and resultant side effects, during periods of rest. PCA offers the advantage of allowing patients to meet their individual and changing needs, including premedication for incident pain. Well-managed epidural analgesia produces more effective analgesia than im injections both at rest and with stimulation.

The authors provided no information to support their conclusion that im injections were "relatively inexpensive." To what are the authors comparing the cost of in injections, and what information do they offer to support the claim? The factors that contribute to the cost of providing pain relief are numerous and difficult to study. Some of them extend well beyond the period of time when a pain relief modality is used, and may be related to such issues as efficacy and safety of the therapy. Although a technique may be incxpensive to provide, if postoperative complications such as fevers, atelectasis, pneumonia, or thrombo-embolic complications are more frequent as a consequence of less effective pain relief, the perccived cost savings may be overshadowed by the costs associated with evaluating and treating those problems. Even a single adverse event involving mortality or serious morbidity associated with providing analgesia can cost millions of dollars.

Dr. Moote in her editorial states that Butscher's study describes an approach to pain management which is "simple, safe and effective." The safety of the approach was not established by this study. Only 53 patients received im morphine. A much larger study would be needed to determine safety when events such as respiratory depression ordinarily occur only rarely. Butscher et al. observed one case of respiratory depression and one case of sedation requiring the patients to be withdrawn from the study. Fourteen additional patients had a respiratory rate less than 12 breaths $\cdot \min ^{-1}$. These observations followed iv morphine titration in the PACU.

There are liabilities to $\mathrm{im}$ injections that were not mentioned by the authors of this study or by Dr. Moote. First, intramuscular injections are painful, traumatic and aversive to many patients. It is not only children who may choose to suffer their incisional pain rather than experience another unpleasant procedure. Second, although it is true that in a perfect world, nurses might be able to check on the adequacy of pain relief on a regular basis (e.g., every hour), in reality, such regular cvaluation is sometimes not possible. Even if nurses were not hesitant to call surgeons for help with problems of inadequate analgesia, the interest and expertise that could be expected in response to such calls is undetermined. One of the advantages of PCA is the independence it affords patients. Medication remains available during periods when the nurse and/or physician may not be.

There is no doubt that costs of medical care must be justified. I support the use of less expensive methods when they provide an acceptable alternative to more costly ones. The question is, who should be the judge of acceptability? We might do well to defer to the consumer, i.e., the patients (who also elect government representatives). If asked which elements of medical care they would be least willing to give up, it is my contention that adequate, safe, pain relief would be at or near the top of the list. I do not think that intramuscular injections, even when used optimally, would be considered an acceptable alternative to more modern methods by a wellinformed general public.

Dr. Moote correctly states that "physician billing is an integral part of any pain service and may be the most expensive component." Although the old economic adage "you get what you pay for" is still valid, I wonder if it is time to give our patients "more than they pay for." Is it timely for us to considcr offering our professional services to our patients in pain after surgery without additional charges? With that approach, modern techniques for postoperative pain management would be made immediately more affordable and our credibility as a specialty which is dedicated both to quality of care and fiscal responsibility would be enhanced. I recognize this would present a major redefinition of our specialty's "job description" but, as Dr. Moote points out, "in the race to reduce cost, we must strive to protect essential services for patients who need them most."

\section{Brian Ready MD FRCPC}

Department of Ancsthesiology

University of Washington

Box 356540

Seattle, WA 98195-6540 USA 


\section{REFERENCES}

1 Butscher K, Mazoit JX, Samii K. Can immediate opioid requirements in the post-anaesthesia care unit be used to deterrnine analgesic requirements on the ward? Can J Anaesth 1995; 42: 461-6.

2 Moote CA. Postoperative pain management - back to basics (Editorial), Can J Anaesth 1995, 42: 453-7.

\section{$R E P L Y$}

Going "beyond basics" in health care is an issue which is currently undergoing intense debate. It is time to define core and comprehensive services." Which services are necessary and which are a luxury? Which services should the public be asked to fund and for which services should the patient be required to pay? The cornerstone for such technology assessment must be evidence-based medicine. New therapeutic procedures must be compared with standard treatments considering safety, efficacy and cost.

Safety - Respiratory arrest ${ }^{2}$ and severe respiratory depression $^{3}$ can and does occur with PCA. Problems have occurred when well-meaning nurses, family and visitors help the patient push the button. Equipment problems are an additional concern. An ampoule of naloxone is routinely at the bedside for patients using PCA. This has never been standard practice for im analgesia.

Efficacy - Changing the technique of administration does not dramatically alter the efficacy or safety of morphine Papers that compared im and PCA analgesia, have found bott to be equally effective. ${ }^{4}$ Inadequate analgesia has also beer reported with $P C A .^{5}$

Cost - The Committee on Pain Management under the Section on Clinical Care in the American Saciety of Anesthesiology has developed pain outcome measures for pair management. In the list of nine pain outcome measuremen. categories the first category listed is cost. ${ }^{6}$ If conventiona. nurse administered opioid analgesia produces a similar out. come at lower cost, it should be adopted as the analgesic tech nique of first choice. In a health care system funded solely by tax dollars, PCA should be reserved for patients who canno be managed by nurse administered analgesia.

Carol A. Moote, MD FRCPC

London, Ontario

\section{REFERENCES}

1 Wyman $M$, Feeley $J$, Brimacombe G, Doucette $K$. Core and comprehensive health care services: 4 . Economic issues. Can Med Assoc J 1995; 152: 1601-4.

2 Zimmerman $D L$, Stewart $J$. Postoperative pain management and Acute Pain Services activity in Canada. Can J Anaesth 1993; 40: 568-75.

3 Etches $R C$. Respiratory depression associated with patient-controlled analgesia: a review of eight cases. Can J Anaesth 1994: 41: 125-32.

4 Wheatley $R G$, Shepherd D, Jackson $I J$, Madej TH, Hunter $D$. Hypoxaemia and pain relief after upper abdominal surgery: comparison of i.m. and parient-controlled analgesia. Br J Anaesth 1992; 69: 558-61.

5 Smythe MA, Martin SE, Schad RF. Retrospective evaluation of patient-controlled analgesia use in a large teaching institution. DICP 1991; 25: 1058-61.

6 Thompson $G E$. Outcome measures defined for pain management. American Society of Anesthesiologists Newsletter 1995; 59: 31-2.

\section{Medication labels: for whose benefit?}

To the Editor:

We wish to report a "near-miss" drug error that was averted because of the report by Ahdal and Bevan. ${ }^{1}$ These authors described a case of prolonged neuromuscular blockade following an overdose of clindamycin. Misinterpretation of the drug label caused the overdose and contributed to a similar incident described below.

Recently, one of the authors (R.C.) was asked to administer clindamycin $(300 \mathrm{mg}$ ) to a patient undergoing general anaesthesia. The prominent text on the clindamycin vial, printed in large blue letters, was "Dalacin C Phosphate." The number " 150 " was the second most prominent feature. In smaller font, "clindamycin phosphate injection USP" was evident. The contents of the two vials $(8 \mathrm{ml})$ were drawn into a syringe in order to prepare a dose of $300 \mathrm{mg}$. The need to open two vials seemed unusual and the report of Ahdal and Bevan came to mind. Upon closer inspection of the vials, "clindamycin/ml" was noted in small print. The syringe, therefore, contained $1200 \mathrm{mg}$, four times the required dose. The dose of clindamycin reported by Ahdal and Bevan was also increased by a factor of four, suggesting Dalacin C Phosphate was involved.

This label (Figure) meets the standards set by the Canadian Society of Hospital Pharmacists, yet it is difficult to read.

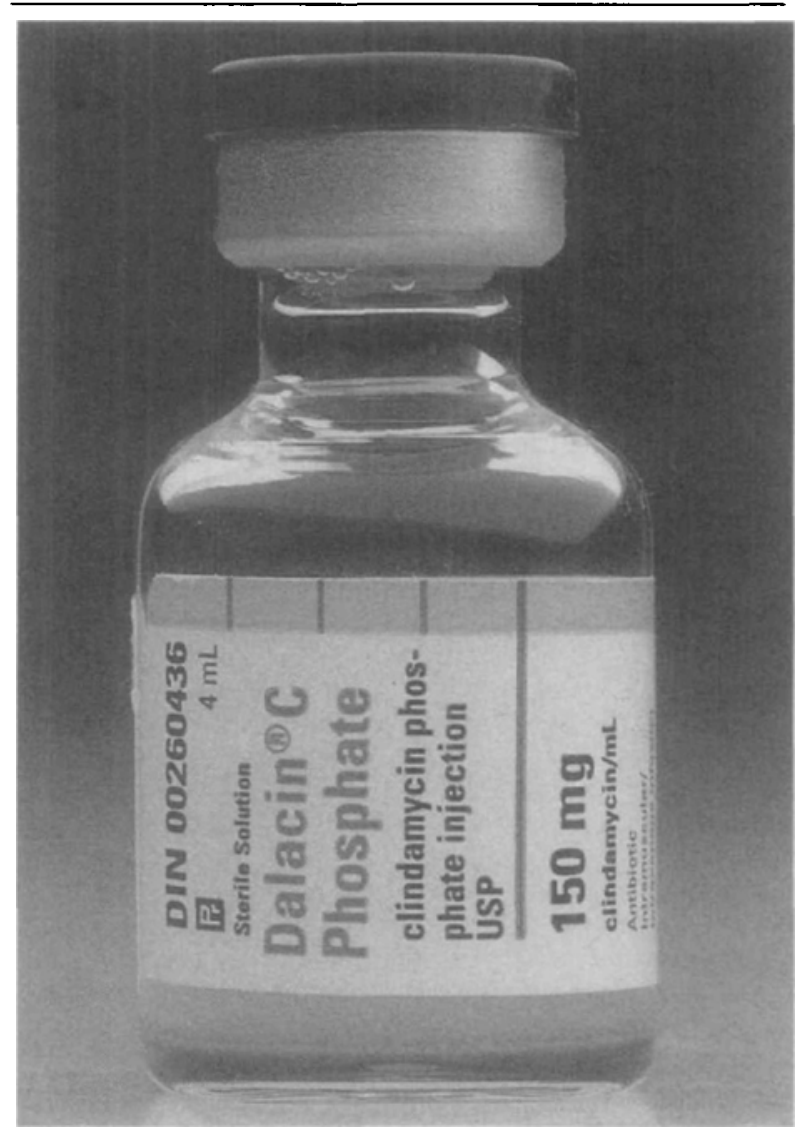

FIGURE 